\title{
CORRESPONDENCE
}

We welcome letters to the Editor concerning articles which have recently been published. Such letters will be subject to the usual stages of selection and editing; where appropriate the authors of the original article will be offered the opportunity to reply.

Letters should normally be under 500 words in length, double-spaced throughout, signed by all authors and fully referenced. The edited version will be returned for approval before publication.

\section{WEDGING CASTS}

Sir,

I read with interest the report on tibial cast wedging by Gregson and Thomas in the May 1994 issue (1994; 76-B:496-7) and agree that their method accurately assesses the size of the wedge. It can, however, be simplified using only a sheet of paper and a pen.

Lines are drawn perpendicular to the long axes of the two fragments ( $a b$ and $\left.a^{\prime} b^{\prime}\right)$ using a sheet of paper as a set square (Fig. 1). As the authors correctly intimate the distance $b^{\prime}$ ' provides too

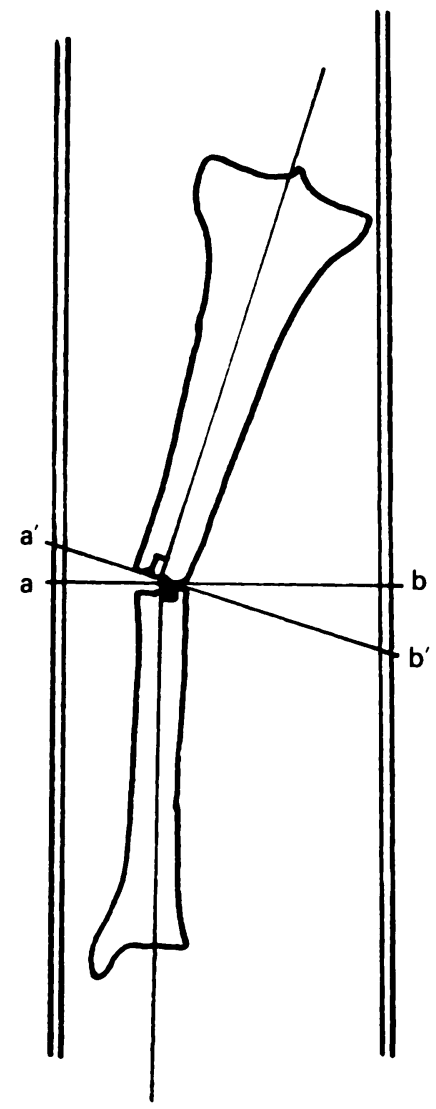

(C)1994 British Editorial Society of Bone and Joint Surgery 0301-620X/94/6928 \$2.00

J Bone Joint Surg [Br] 1994; 76-B:991-5. small a wedge; the hinge is at the cast rather than at the fracture site. If this distance, however, is increased by aa' (easily marked off on the edge of the paper) this gives the correct size of wedge which can then be marked on the plaster. In practice, I find that the fact that $\mathrm{aa}^{\prime}$ and $\mathrm{bb}^{\prime}$ are parts of right-angled triangles rather than isosceles triangles compensates well for the amount of wedge opening which takes place before there is any movement at the fracture site.

This method has proved to be reliable, reproducible and effective.

R. M. KERRY, FRCS

Chesterfield Royal Hospital NHS Trust

Derbyshire, UK.

Gregson PA, Thomas PBM. Tibial cast wedging: a simple and effective technique. J Bone Joint Surg [Br] 1994; 76-B:496-7.

\section{IMAGING IN SPINAL TUBERCULOSIS}

Sir,

In the article entitled 'Imaging in children with spinal tuberculosis' (1993; 75-B:233-9) Hoffman, Crosier and Cremin state that CT and MRI provide the best preoperative evaluation of patients who require surgical treatment for paraplegia. One of the factors causing paraplegia is anterior spinal artery occlusion, which can be detected by angiography. We use this at the King Edward Memorial Hospital, Bombay and reported this in the Indian Journal of Orthopaedics (1990), later quoted in Paraplegia (1993). We consider that this investigation should be added to preoperative evaluation before either decompression of the spinal cord or curettage.

\author{
V. A. MITTAL, MS (Orth) \\ 5 Sunrise \\ 3rd Pasta Lane \\ Colaba \\ Bombay, India.
}

Hoffman EB, Crosier JH, Cremin BJ. Imaging in children with spinal tuberculosis: a comparison of radiography, computed tomography and magnetic resonance imaging. J Bone Joint Surg [Br] 1993; 75-B:2339.

Mittal VA. Anterior spinal artery angiography in Pott's paraplegia. Ind J Orthop 1990; 24:57-9 and Paraplegia 1993; $31: 73$.

Author's reply:

Sir,

Dr Mittal's study reports the age of only one patient who was 25 years. Our article concerned only children, who have a better prognosis for paraplegia than adults.

All our children with paraplegia who had a good outcome, had extradural compression caused by an abscess (i.e. fluid, caseous pus or granulation tissue), shown on MRI by an increased signal on a T2-weighted image. The duration of paraplegia was less than three months. Both during and subsequent to our study, we found that neurological involvement caused by an abscess in a child recovers with antituberculous treatment without surgery.

We have not seen cord ischaemia in children, although we have seen adults with a short history of paraplegia and an extradural abscess who did not recover after anterior decompression. This was probably due to ischaemia caused by cord compression or anterior spinal artery thrombosis. In these patients focal myelopathy was 